\title{
A Escola Superior de Educação Física e o campo da formação de professores do estado sul-rio- grandense: as origens da formação especializada (1869-1929)
}

\author{
Vanessa Bellani Lyra* \\ Janice Zarpellon Mazo**
}

\begin{abstract}
Resumo: A fundação da ESEF esta inserida em um processo social, no qual a sociedade sul-rio-grandense foi mobilizada para $o$ alcance de finalidades que, antes mesmo de corresponderem a suas particularidades sociais, remetiamse à consolidação de um novo Brasil, país que então emergia enquanto organização política republicana. Assim, em nosso entendimento, qualquer tentativa de distinguir a ESEF enquanto primeira instituição de ensino a formar professores em nível superior no Estado, passa, necessariamente, pelo conhecimento dos esforços de sistematização desta prática formativa, que antecederam a sua chegada ao campo. De tal modo, o objetivo central do estudo foi o de compreender como ocorreu a formação de professores de Educação Física no período anterior a institucionalização da ESEF. Para tanto, o reconhecimento e a validade de novas versões sobre nosso objeto de estudo, bem como a utilização de fontes que anunciem procedências e naturezas diversas são elementos que compõe uma forma particular de apropriação da história, da qual procuramos aqui nos aproximar: a História Cultural. Nesse espectro, nossas investigações acerca do tema nos levaram a pontuar dois momentos significativos que atravessaram o campo nesses momentos iniciais: a ausência de formação especializada e, a partir do ano de 1929, a organização dos chamados "Cursos Intensivos de Educação Physica".
\end{abstract}

Palavras-chave: História. Educação Física. Formação de Professores.

\footnotetext{
'Doutoranda do Programa de Pós-Graduação em Ciências do Movimento Humano da ESEF/ UFRGS. Pesquisadora do Núcleo de Estudos em História e Memória do Esporte e da Educação Física, vinculado ao Programa de Pós-Graduação em Ciências do Movimento Humano, da UFRGS. Porto Alegre, RS. Brasil

**Professora dos cursos de Licenciatura e Bacharelado em Educação Física e Programa de Pós-Graduação em Ciências do Movimento Humano da ESEF/ UFRGS. Coordenadora do Núcleo de Estudos em História e Memória do Esporte e da Educação Física, vinculado ao Programa de Pós-Graduação em Ciências do Movimento Humano, da UFRGS. Porto Alegre, RS. Brasil
} 


\section{INTRODUÇÃO}

Os investimentos que se faz para percorrer uma perspectiva histórico-cultural de análise, muito mais que uma escolha meramente acadêmica reflete, pois, num sentido mais amplo, posicionamentos que são assumidos pelo pesquisador diante de sua vida cotidiana. Em outras palavras, talvez pouco científicas, o que aqui queremos afirmar é o fato de que a vida e a arte de estudar a vida por meio da História se configuram em uma visão particular de mundo, onde as estimas pessoais não conseguem permanecer imunes às irradiações de um determinado referencial teórico. A direção geradora deste processo de influências é, porém, difícil de identificarmos: afinal, uma moeda tem sempre dois lados. Mas isso, certamente, não é o que mais nos importa. Ao debruçarmo-nos sobre a pesquisa em História do Esporte e da Educação Física o que buscamos, incessantemente, é a entrega do eu pesquisador ao objeto de análise em questão, tanto quanto aos contornos assumidos pelos modos e pelas formas de a ele nos aproximar.

Nesse sentido, o ato de entregar-se que é exigido do pesquisador, está sujeito ao encontro de conhecimentos não previstos, não determinados e não encerrados pela força do tempo ou pelo poder legitimador que emana de uma determinada fonte. $\mathrm{O}$ reconhecimento e a validade de novas versões sobre certo objeto, bem como a utilização de fontes que anunciem procedências e naturezas diversas são elementos que compõe uma forma particular de apropriação da história, da qual procuramos aqui nos aproximar: a Nova História Cultural. Deste modo, para além do conhecimento das verdades históricas consolidadas, o inesperado torna-se, assim, objeto de desejo das pesquisas inseridas nesta tradição.

Em nosso entendimento, qualquer tentativa de compreensão da ESEF enquanto primeira instituição de ensino a formar professores em nível superior no Estado, passa, necessariamente, pelo conhecimento dos esforços de sistematização desta prática formativa, que antecederam a sua chegada ao campo. Certos como estamos, de que sua emergência, em 1940, guarda relações de 
proximidade e de afastamento com as formas de se pensar a formação especializada anteriores a si, encontramos em Calvino (2004) a expressão que nos ajuda a justificar esta idéia de continuidade histórica a qual aqui defendemos:

[...] isolar uma onda da que se lhe segue de imediato e que parece às vezes suplantá-la ou acrescentar-se a ela e mesmo arrastá-la é algo muito difícil, assim como separá-la da onda que a precede e que parece empurrá-la em direção à praia, quando não dá até mesmo a impressão de voltar-se contra ela como se quisesse fechá-la [...] Em suma, não se pode observar uma onda sem levar em conta os aspectos complexos que concorrem para formá-la e aqueles também complexos a que essa dá ensejo (CALVINO, 2004, p. 7-8).

Deste modo, tomando por empréstimo as palavras de Calvino, nosso objeto de análise neste estudo privilegia o entendimento da onda que precede a chegada da ESEF ao campo da formação de professores no estado do Rio Grande do Sul. De outro modo, nossos esforços estão aqui concentrados na compreensão daquela onda que, tendo sua formação ao alvorecer da ESEF, parece "empurrá-la em direção à praia" e que, por isso mesmo, torna sua análise muito significativa e inseparável de uma compreensão da própria Escola que se pretende mais ampla.

No que tange a nossa contribuição para este volume especial da Revista Movimento, no qual são compilados trabalhos que privilegiam a comemoração dos 70 anos de vida da Escola de Educação Física (ESEF) da Universidade Federal do Rio Grande do Sul (UFRGS), nossa principal preocupação foi compilar indícios históricos sobre a formação de professores para atuar na Educação Física no período anterior a fundação da ESEF. Consideramos que os momentos iniciais da consolidação do campo criaram condições para que em 1940 entrasse em funcionamento o primeiro curso superior em Educação Física no estado do Rio Grande do Sul. Nesse sentido, o objetivo do estudo foi o de compreender a ESEF como parte de um processo social, em que a sociedade sul-rio-grandense foi mobilizada para o alcance de finalidades que, antes mesmo de 
corresponderem a suas particularidades sociais, remetiam-se à consolidação de um novo Brasil, país que então emergia enquanto organização política republicana.

Para tanto, uma vasta gama de fontes históricas foi consultada: tratou-se da incursão sobre os Relatórios e Mensagens Anuais expedidos aos órgãos públicos brasileiros, jornais de circulação estadual, leis, atos, decretos, periódicos especializados, dentre outras. Tais fontes foram submetidas à análise documental, cujas informações são apresentadas nos tópicos que seguem.

Entre tantas outras possibilidades de organização, os conhecimentos adquiridos em torno desta questão obedecem ao seguinte arranjo estrutural neste texto: A Educação Física na Construção da Instrução Pública no Rio Grande do Sul; e A criação dos Cursos Intensivos de Educação Física em Porto Alegre.

\section{A EduCAÇÃo Física na CONSTRUÇÃo da INSTRUÇÃo PÚBLICA No Rıo Grande DoSul}

Ainda que sempre presente a sensação fugidia de pontuarmos a origem dos fatos históricos, lançamo-nos aqui ao desafio (transitório) de afirmarmos que as primeiras tentativas de se estabelecer uma sistematização para a formação de professores de Educação Física no Rio Grande do Sul, se deu, a partir da criação da primeira Escola Normal de Instrução Primária, na capital do Estado. Tal Escola, anexa ao então Liceu Dom Afonso foi criada no ano de 1869, com o objetivo de proporcionar uma melhor preparação profissional aos professores das escolas sul-rio-grandenses de $1^{\circ}$ grau. Há indícios que, no entanto, a cadeira de Ginástica fora inserida no currículo escolar apenas no ano de 1877, portanto, oito anos mais tarde.

De acordo com Piccoli (1994, p. 20), o primeiro professor a assumir a cadeira de Ginástica na referida Escola foi Edmundo Muniz de Bittencourt. Longe de operarmos em uma forma linear de historiografia, na qual erroneamente estaríamos a generalizar uma 
situação particular, não podemos considerar uma coincidência o fato de que, assim como se desenhava o quadro do professorado em Educação Física no país, Bittencourt era militar, respondendo pelo posto de capitão do $13^{\circ}$ Batalhão de Infantaria do Exército. É interessante destacarmos que Bittencourt exercera função docente semelhante na Escola Militar no Rio de Janeiro, até o ano de 1882 onde, diferentemente dos demais professores, recebia a titulação de "mestre de ginástica".

Assim, despedindo-se, aos poucos, dos ditames imperiais e de toda a visão de mundo que lhe era cara, a República Federativa do Brasil emergia, a partir de 1889, impulsionada por um ideário político que reclamava por mudanças sociais de toda ordem. Imerso em um contexto profundamente conturbado, atravessado pelas inseguranças e pelo terror da guerra, o novo regime anunciava sonhos e ideais de um país que se pretendia ao alcance de todos ao lutar em defesa da emancipação social dos cidadãos brasileiros. Era necessário, assim, reorganizar as estruturas sociais vigentes, adotando em suas bases um discurso unificador em prol do bem público: ao novo Brasil, "conservar, melhorando" (CASTILHOS, 1895, p. 12).

Neste contexto, onde a sociedade brasileira de uma forma ampla foi mobilizada pela atmosfera revolucionária republicana de modernização conservadora, os elementos históricos nos permitem perceber que a conjuntura estabelecida em fins do século XIX e início do século $\mathrm{XX}$, nos apontam para um duplo movimento de transformação: o abandono da velha ordem e, a consequente constituição de outra. Assim, neste cenário de reconstrução, a instrução pública, ou seja, a educação ocorrida nas escolas recebeu espaço significativo dentre as preocupações norteadoras do novo regime ${ }^{1}$.

\footnotetext{
${ }^{1} A$ instrução primária e secundária foi regulamentada através da reforma do ensino realizada por Benjamin Constant, no final do ano de 1890. Cada escola deveria ter, além de salas de aula, biblioteca e museu, um ginásio para exercícios físicos e um pórtico de madeira para a realização dos exercícios ginásticos. Conforme Piccoli (1994), em homenagem a esse reformador do ensino brasileiro, fundou-se a Escola Benjamin Constant de Instrucção elementar e Profissional. A escola, inaugurada no dia 3 de maio de 1907 era dirigida pela Escola de Engenharia e destinava-se aos filhos de operários e meninos pobres de Porto Alegre.
} 
Compreendida no rol dos elementos fundamentais para a consolidação do novo projeto, a escola pública despontava, assim, como uma das instituiçõoes sociais que urgia por reformulações fulcrais em sua estrutura, meios e fins. Deste modo, anunciando uma inspiração fortemente positivista ${ }^{2}$, os documentos republicanos advogavam uma idéia de educação enquanto processo de adaptação do indivíduo ao meio social. Seguindo este ideário, tal processo deveria ser controlado, até certo ponto, pela ação agregadora do estado:

O ensino público, ainda subordinado, salvo algumas modificações secundarias, ao regulamento provincial carece de uma reorganisação quasi radical, que o colloque em condições de ser mais eficazmente ministrado e divulgado. Acha-se em estudos um projecto de regulamento que, em principios do anno vindouro, poderá entrar em vigor (CASTILHOS, 1895, p. 15).

O projeto ao qual se referia o então presidente do Rio Grande do Sul, Julio Prates de Castilhos, entrou em vigor, em forma de decreto (Decreto n. 89), na data de 2 de fevereiro de 1897. Desde seu anúncio, já há dois anos antes, tal projeto carregava consigo a promessa de equiparação da instrução pública sul-rio-grandense aos demais ramos do serviço estadual, no que tange à qualidade de organização. Ao que parece, por motivos de insuficiência orçamentária $^{3}$, havia um grande contraste entre as ampliações e progressos que ocorriam nos demais departamentos da administração pública, e aqueles delineados pelo campo da educação.

A Reforma apresentava, pois, uma natureza grandiosa a ser reestruturada. Caracterizava-se, entre outros predicados, pela

\footnotetext{
${ }^{2}$ Para uma melhor compreensão do pensamento positivista sobre a Educação ler "Educação e Sociologia", obra escrita por Emile Durkheim, publicada no ano de 1932 (obra póstuma).

${ }^{3}$ Ao que nos apresentam as fontes históricas consultadas (CASTILHOS, 1896, p. 14), grande parte do orçamento destinado à construção de obras públicas, sobretudo aquelas referentes à educação, é proveniente das rendas da Loteria Federal. No ano de 1896, por exemplo, as fontes apontavam a importância de 107:520 $\$ 000$ para mobilizar a construção de prédios escolares, adaptados às escolas distritais. A começar tais edificações pela capital do Estado, o projeto previa a adequação das instalações ao funcionamento dos três graus do ensino primário.
} 
garantia da estabilidade, pela fiscalização permanente e segura, pela unidade de direção, tão ausente nas escolas da corte, pela laicidade, liberdade e gratuidade do ensino, além da divisão deste em elementar e complementar. De um modo particular, a Reforma reclamava como sua a responsabilidade "pela aptidão profissional e moral do professorado e de todos aquelles que exercem funcções de direcção e inspecção" (CASTILHOS, 1897, p. 16). Dentre as primeiras ações a serem realizadas, estava prevista a construção de prédios apropriados à educação da infância, guiados por sua vez, pelos preceitos "hygienicos e pedagógicos" (CASTILHOS, 1896, p. 13).

No que se refere à inserção do campo da Educação Física no Rio Grande do Sul na legislação oficial do ensino, a Reforma de 1897 desponta em seu pioneirismo. Seus ditames legais anunciavam que, a partir deste momento, tanto o ensino ministrado nos colégios distritais, quanto aquele ocorrido nas escolas complementares, estaria caracterizado pela inserção da cadeira de ginástica em sua grade curricular. No entanto, até onde nos direcionam nossas fontes históricas, a obrigatoriedade legal da disciplina nos currículos de formação docente, não foi um elemento forte o suficiente para garantir a real presença desta nos currículos escolares, e nem mesmo a qualidade do ensino que era oferecido.

Assim, no que tange à formação de professores de Educação Física no estado sul-rio-grandense, nas três primeiras décadas do século XX, algumas carências podem ser evidenciadas. O quadro inicial de professores que aqui se delineava, reproduzia o quadro mais geral do país, onde a falta de professores habilitados figurava como um dos principais problemas enfrentados pelo campo que pretendia se legitimar. Nesse contexto, $\operatorname{Mazo}(2005$, p. 148) ratifica que a situação em questão se agravava à medida que a importância atribuída aos benefícios da Educação Física e do esporte crescia com a necessidade de "assistência de técnicos especializados". Assim, não havia professores de Educação Física em número suficiente para atender as escolas e as novas demandas provenientes das associações esportivas. 


\section{Acriação dos CuRSOS INTENSIVOS de EduCAÇÃo FísICA EM Porto Alegre}

Preparemos a escola primária activa [...] sem esquecer, entretanto, que o melhor methodo de ensino é o professor que se aperfeiçoa todos os dias. Tal professor, tal escola (ARANHA, 1929, p. 7).

O ano de 1929 rompeu e, com ele, o anúncio de novos rumos ao campo da formação de professores de Educação Física no estado do Rio Grande do Sul. Autorizado a funcionar pelo governo do Estado, sob a direção vigilante do inspetor estadual de Educação Física professor Frederico Guilherme Gaelzer, o Curso Intensivo de Educação Física é criado na capital demarcando os esforços iniciais de se estabelecer uma formação específica para o trabalho docente na área.

Distantes ainda uma década daquele que anos mais tarde se configuraria como o primeiro curso superior de formação no Estado, a Escola Superior de Educação Física, nossa leitura acerca desta sistematização inicial nos leva a compreendê-la a partir de um duplo juízo de seus arranjos: se ainda sensíveis e frágeis para edificar as bases estruturais de um campo específico; já fortes e acreditados para impulsionar tais bases adiante. Em outras palavras, ainda que o Curso Intensivo de Educação Física pareça ter como resultado um alcance relativo diante das demandas educacionais que reclamavam por mão-de-obra especializada, sua criação, além de outros aspectos, pode ser considerada os primeiros passos rumo à diferenciação e à especificação de uma nova identidade profissional: a professora normalista especializada em Educação Física.

Se a Escola Normal era um espaço ocupado quase que exclusivamente pelo público feminino, o mesmo se dava nos Cursos Intensivos de Educação Física. Não raras vezes a documentação consultada referia-se exclusivamente a professoras, em suas obrigações ou prerrogativas, como também as imagens trazidas pelas páginas dos jornais da época retratavam, recorrentemente, o inspetor Gaelzer ladeado por um grupo de mulheres recém formadas pelo 
referido curso. Assim, a matrícula era somente permitida aos candidatos diplomados em escolas normais e complementares, ou estabelecimentos congêneres, que se incluíssem na faixa etária entre 19 e 30 anos (OS MODERNOS METHODOS DE ENSINO, 1929).

Com vistas à ocupação de um espaço que passava a ser importante no ambiente escolar, as jovens professoras eram então socializadas às "modernas formas" de se conceber e de se ensinar a Educação Física. O adjetivo "moderno" passou a acompanhar a expressão "Educação Physica" de forma recorrente na literatura e na documentação da época, expressando a clara intenção de se obter uma nova identidade tanto às práticas e às formas de se praticar quanto aos meios e fins do que se pretendia ser a nova Educação Física. O estado sul-rio-grandense se coloca, nesse momento, em compasso com as aspirações nacionais de construção de uma individualidade modernizada a partir da pedagogia moderna que se desenhava na escola. Assim, entre tantos outros elementos educativos que concorriam a esse fim, a criação da cadeira de Educação Física nas escolas primárias, no início de século XX e, posteriormente, sua obrigatoriedade no ensino regular, pode ser entendido como um dos principais direcionamentos desse grande feito ${ }^{4}$ ocorridos no Estado.

É interessante pontuarmos que, nesses momentos iniciais, a Educação Física no Brasil era influenciada pelas correntes ou "métodos" ginásticos europeus - o alemão, o sueco e o francês baseados, por sua vez, em princípios biológicos. Tais moldes, de acordo com Piccoli (2005, p. 503), estavam inseridos num movimento mais amplo, de natureza política, cultural, e científica, denominado Movimento Ginástico Europeu. Dentre tais Escolas, a alemã recebe destaque no cenário sul-rio-grandense, no início do século $\mathrm{XX}$, entre outras razões, pela influência educativa do imigrante alemão Georg

\footnotetext{
${ }^{4} \mathrm{Na}$ esfera nacional, a Constituição Federal de 1937, em seu artigo 131, determinou que educação física, o ensino cívico e o de trabalhos manuais seriam obrigatórios em todas as escolas primárias, normais e secundárias. A obrigatoriedade da Educação Física no estado do Rio Grande do Sul, do ensino primário até o normal foi determinada pelo Decreto-Lei n. 8.063 de 10/10/1945, no artigo 100: "A educação física, o ensino cívico e o de trabalhos manuais serão obrigatórios em tôdas (sic) as escolas primárias, normais e secundárias" (RIO GRANDE DO SUL, 1990, p. 139).
} 
Black e de seus ensinamentos de ginástica alemã, nas sociedades de ginástica e escolas estaduais ${ }^{5}$.

É justamente nesse quadro de influências culturais heterogêneas atuando sobre a cultura física que se desenvolvia no Brasil, que será lançado, em 1921, o Decreto n. 14.784, que estipulava a substituição do Método Alemão pelo Método Francês e, concomitantemente, a adoção, deste último, como o "método oficial" a ser incorporado no país, enquanto não fosse criado o próprio "Método Nacional"6. Tal investida contou com a participação fervorosa de intelectuais envolvidos com o ideário da renovação nacional pela renovação educacional, ao defenderem que o "antigo" método, culpabilizado pelo reducionismo materialista que encampava a atual situação da prática física escolar, fazia-se partícipe do conceito de uma "velha" Educação Física ${ }^{7}$.

O consenso que se estabelecia no Estado, em torno da necessidade do empreendimento de um trabalho pedagógico

\footnotetext{
${ }^{5}$ Sobre o tema, ler MAZO, J. Z.; LYRA, V. B. Georg Black: nos rastros da trajetória do "pai da educação física e dos esportes no Rio Grande do Sul".

${ }^{6}$ Victor Andrade de Melo (1996, p. 42) expõe, em seu estudo, que dentre as expectativas que encerravam a criação da Escola Nacional de Educação Física e Desportos, no ano de 1939, encontrava-se a criação, consolidação e divulgação, às demais escolas de Educação Física do país, do "método nacional". Em suas conclusões, desveladas, sobretudo, a partir da utilização de fontes orais, encontra-se a proximidade da estrutura pedagógica então vigente na referida escola, com àquela que sustentava a lógica da Escola de Educação Física do Exército. Assim, a "inovadora" criação de uma escola-padrão, destinada à formação de professores ao meio civil, é apresentada pelo autor na continuidade e na força persistente dos ideais militaristas, interessados tanto na atividade catedrática quanto, num sentido mais amplo, na manutenção de seus interesses no campo. Melo aponta ainda, que, a Escola de Educação Física do Exército, instituição fundada do ano de 1933, baseava suas ações nos parâmetros educacionais ditados pela escolafrancesa, de Joinville-Le-Pont.

${ }^{7}$ Ainda que defensores da adoção do Método Sueco, como método oficial no Brasil, Rui Barbosa (1882) e Fernando de Azevedo (1960) participaram ativamente na construção de um pensamento contrário aos ideais e objetivos trazidos à Educação Física brasileira, pelo então corrente Método Alemão. Para uma Educação Nova, Azevedo advogava uma Nova Educação Física que, a exemplo de Barbosa, condenava ao fatalismo errôneo as finalidades extremas de exercitação do corpo, sustentadas a partir de prejuízos aos atributos intelectuais e morais. Sendo ponto passivo no pensamento de ambos, o exagero da exercitação dos músculos que encontravam em si sua razão de ser, nada contribuía com alguma utilidade ao momento de transição em que se encontrava a sociedade brasileira, nem tampouco com as exigências de construção de um novo indivíduo social. Afinal, no entender de Azevedo, no novo projeto de sociedade, baseado nas trocas, nas relações de competição mercadológica, deve-se buscar uma educação pelo esforço, pela fadiga enquanto meio educativo e não desvirtualizador da moral ou da valorização de sentimentos egoístas, prejudiciais ao "engrandecimento social" (LYRA, 2009).
} 
unificado, era, portanto, impulsionado pelo ideal de construção de um "espírito nacional" caracterizado, entre outros, por valores como identidade, laboriosidade, religiosidade, racionalidade e sanidade, como nos aponta Vieira (2004). Nesse quadro de mudança civilizadora do comportamento, que atravessava o país entre os anos de 1920 e 1930, a Educação Física escolar surge no cenário educacional nacional, como um espaço educativo privilegiado para a legitimação desse novo processo. Nesse passo, se o projeto de reconstrução nacional deveria passar pela reformulação dos currículos escolares, adequando-os às novas aspirações e fins educacionais; a necessidade de formar professores especializados, socializados às modernas técnicas e formas de ensinar, emergia como elemento fundamental e complementar aos êxitos do processo.

Fazia-se imperativo, portanto, pensar a formação de professores especializados. A Educação Física representava um elemento importante demais para o alcance dos objetivos nacionais, para que um ensino desqualificado e destoante dos modernos métodos fosse admitido como condutor do processo educativo: abria-se, assim, um novo campo dentro da Educação Física brasileira. Na mesma medida, Bombassaro e Vaz (2008) apontam ainda que, o referido sentido compartilhado de criação de uma identidade ao povo brasileiro, que outrora animava e aquecia a política educacional do país, era traduzido, entre outros, nos currículos dos cursos de formação docente, que pretendiam engendrar um modelo de referência, sintonizado com os tempos modernos.

À aurora do Novo Brasil era imperioso forjar o "novo" homem e nenhum elemento parecia concorrer tão fortemente a tal princípio quanto a educação. Sendo, pois, a Educação Física a parte física da educação, ficaria sob sua responsabilidade a incumbência de ser um espaço que oferecesse subsídios para "[...] forjar aquele indivíduo 'forte', 'saudável', indispensável à implementação do processo de desenvolvimento do país" (CASTELLANI FILHO, 1991, p. 39) e aos seus mestres, a "missão" de a um só tempo ser o retrato e o realizador deste grande feito. 
Assim, esta grande importância que a disciplina Educação Física passou a assumir em cenário nacional irradiou-se, também, para a figura do professor de Educação Física. Não por acaso, os jornais da época que veiculavam notícias sobre a criação do Curso Intensivo, na capital gaúcha, anunciavam em suas linhas o teor de tal significado. No rol das influências favoráveis ao desenvolvimento da criança presentes na educação moderna, a mais fortemente valorizada era direcionada aquilo que se compreendia como os valores morais e profissionais do mestre:

A' professora de educação physica exigir-se-ão, portanto, além de um cabedal technico apreciavel, determinadas qualidades: liderança, elevação moral, enthusiasmo, ideaes superiores, saude physica, etc. Desse modo, não só poderá dirigir a educação physica, baseando-a no conhecimento da natureza infantil e das necessidades individuaes, como será constantemente para a sua classe um elevado padrão moral, um exemplo vivo e suggestivo (OS MODERNOS METHODOS DE ENSINO, 1929, p. 22).

Complementando a idéia da responsabilidade moral que cabia aos professores de Educação Física, o curso em questão contaria com a participação das diretoras escolares no que tange à indicação de seus representantes. Cada diretora deveria eleger três de seus auxiliares "dotados das aptidões que se fazem mistér" (OS MODERNOS METHODOS DE ENSINO, 1929, p. 23), para participarem da formação oferecida. Lembrando da conveniência desta escolha, a notícia veiculava ainda a idéia de que tais qualidades não eram reunidas por todas as pessoas e nem tampouco eram adquiridas "no maneio dos livros ou nos bancos da escola" (OS MODERNOS METHODOS DE ENSINO, 1929, p. 23).

Ao que se apresenta diante de nós, havia uma preocupação latente em fazer com que a educação do corpo estivesse articulada à educação dos espíritos e das mentalidades. Reiterando os parâmetros anunciados pela educação moderna, a escola deveria defender a idéia de educação integral, na qual os objetivos e esforços pedagógicos recairiam sobre o equilíbrio da atenção dada ao corpo, 
à mente e ao espírito. Nesse sentido, mais do que um bom executor de meras ações mecânicas restritas somente à dimensão física, o professor de Educação Física deveria apresentar qualidades de cunho moral e ético a fim de que a partir de sua prática, fosse capaz de transpor as barreiras de uma educação meramente corporal.

Entre outras fontes, tal prerrogativa pode ser constatada na análise das propagandas que os colégios lançavam a respeito de si, nas páginas de periódicos educacionais da época. Ainda que diferentes em algumas diretrizes estruturais, como o caso das escolas de educação confessional, a idéia de uma educação integral, preocupada com as diversas dimensões a serem aprimoradas na criança e no jovem, emergia a partir de alguns conceitos relacionados com o tema. O extrato a seguir nos dá um exemplo da atenção dada à educação do físico, no arranjo de uma proposta educacional que se pretendia integral e, portanto, moderna:

Ginasio Cruzeiro do Sul: Fundado em 1912, sob inspeção federal desde 1932. Internato para rapazes - seminternato mixto - educação intelectual, fisica, moral e civica - excelente corpo docente. Drama escotismo - escola de instrução militar - grande laboratório, confortáveis instalações, estádio em construção (GINÁSIO CRUZEIRO DO SUL, 1939, p. 147, grifos nossos).

O programa do Curso Intensivo de Educação Física, comungando destes preceitos educacionais, pretendia-se unificador das "práticas de gymnastica dirigidas pelos elementos do magistério sul-rio-grandense" (EDUCAÇÃ̃ PHYSICA, 1929, n.p.). Com duração mínima de dois meses, privilegiando as férias escolares de verão, o programa era compreendido a partir da articulação de conhecimentos teóricos e práticos, dos quais, dentre os primeiros, figuravam "lições de anatomia e physiologia e, dentre os últimos, a execução de jogos diversos e natação" (EDUCAÇÃO PHYSICA, 1929, n.p.). As aulas, ministradas junto à sede da Inspetoria de Educação Física no pavimento de ginástica que o Estado possuía nas dependências do Colégio Estadual Paula Soares, eram norteadas pelo seguinte programa curricular: 
1. $^{0}$ - Organização e administração da Educação Physica; 2. ${ }^{\circ}$ - Bases scientificas da organização das séries callisthenicas; $3^{\circ}$ - Theoria e pratica dos jogos gymnasticos e de todos os desportos; $\mathbf{4}^{\mathbf{0}}$. - Pratica da direcção e controle dos jogos; $\mathbf{5}^{\mathbf{0}}$. - Theoria e pratica de marchas (ordinárias, correctivas, de precisão, etc.); $\mathbf{6}^{\mathbf{0}}$. - Theoria e pratica de exercícios rythmicos e danças gymnasticas; $\mathbf{7}^{\mathbf{0}}$. - Didactica theorica e pratica da Educação Physica; $\mathbf{8}^{\circ}$. Antropometria pedagógica e primeiros auxílios; $\mathbf{9}^{\mathbf{0}}$. - Relação da Educação Physica com os demais ramos de ensino, (opportunidades educacionais, quanto á disciplina, á sociabilidade, á cooperação e fraternidade esportiva); $\mathbf{1 0}^{\mathbf{}}$. - Estudo das condições materiaes dos locaes destinados ás aulas de Educação Physica (OS MODERNOS METHODOS DE ENSINO, 1929, grifos nossos).

Consta, ainda, que desde a primeira edição do curso, no ano de 1929, este já fora alvo de uma grande procura por parte dos professores do interior do Estado. Seduzidos, ao mesmo tempo, pelas novas propostas educacionais e pelos novos horizontes que se abriam no mercado de trabalho, os professores que se candidataram à nova especialização deveriam, primeiramente, apresentaram-se na Diretoria Geral da Instrução Publica, para então serem encaminhados ao referido curso (EDUCAÇÃO PHYSICA ,1929, n.p.).

É interessante pontuarmos que tais candidatos, ao procurarem matrícula no curso intensivo, estiveram sujeitos a uma rigorosa inspeção de saúde realizada pelos inspetores médicos escolares (EDUCAÇÃO PHYSICA, 1929, n.p.). Mais interessante ainda, é analisarmos o fato de que portar plena saúde, mais do que um prérequisito meramente burocrático, aparece como condição primordial para a possibilidade de se acessar ao curso de formação em questão. Assim, nossa leitura nos conduz a pensar que a idéia do grandioso exemplo que o professor de Educação Física deveria ser aos seus futuros alunos, parece aqui encontrar seu complemento: mente, espírito e corpo físico, em equilíbrio eficiente de suas funções, deveriam irradiar uma imagem pedagógica de saúde. 
De outro modo, podemos pensar no fato de que o corpo físico representou, para a escola moderna brasileira de um modo amplo e, sul-rio-grandense, de um modo particular, a possibilidade da tão advogada educação integral. Se como vimos anteriormente, o espaço destinado às práticas escolares de Educação Física no estado sul-rio-grandense do início do século XX quando não inexistente, configurava-se como um elemento curricular de segunda ou terceira ordem; a partir de algumas ações concretas, levadas a cabo, sobretudo, após a criação do curso intensivo de 1929, a situação da referida disciplina começa a assumir novos contornos. Assim, preocupar-se com a educação do corpo dos futuros alunos, passava prévia e necessariamente, pela preocupação com a educação do corpo dos próprios professores. Esta, por sua vez, agiria sobre corpos selecionados, capazes de representar e sustentar a nova identidade que se pretendia dar à Educação Física no Estado.

Bourdieu (1998, p. 98-99), por sua vez, ao lançar-se ao estudo dos elementos recorrentes aos rituais sociais entendidos como ritos de instituição, revela que o efeito principal causado pelo rito é justamente o que passa, na maioria das vezes, completamente despercebido: "o rito consagra a diferença, ele a institui [...] e instituir é consagrar, ou seja, sancionar e santificar um estado de coisas, uma ordem estabelecida". Sendo assim, no rastro do autor citado, entendemos que a investidura da diferença exercida por tal processo "quase mágico" que se esforça por atribuir propriedades de natureza social como se fossem propriedades de natureza natural", mostra sua outra face ao exigir/criar/ratificar uma identidade particular pretendida ao conjunto de alunos selecionados a frequentar o Curso Intensivo de Educação Física.

Sob a mira de olhares atentos e interessados, fomentados pelas mais diversas expectativas que encerravam a criação do curso, a escolha do conjunto de alunos aptos, em oposição ao seu complemento, ou seja, o conjunto de todos os outros, constituía-se, portanto, como peça-chave do projeto de legitimação e de conquista de um espaço no campo o qual o curso intensivo se propôs a conquistar. Sendo assim, o conjunto de alunos eleitos deveria legitimar 
e ser a expressão - nas formas, nos valores, nos objetivos e nas finalidades - da identidade que a Educação Física sul-rio-grandense se esforçava por construir e outorgar a si mesma.

Caminhando neste mesmo sentido, em torno desta questão identitária, não raras vezes encontramos nos documentos consultados a articulação da expressão "Educação Física" com outras de cunho utilitário, como "fortalecimento da raça", "aperfeiçoamento da raça", "hygidez do corpo". Neste momento de remodelação estrutural pelo qual atravessava a Educação Física no Estado, tais preceitos eram facilmente identificados não somente no que tange à formação de professores especializados como, também, nos espaços de atuação que a estes profissionais se reservavam.

Para além das escolas primárias, secundárias e normais, a atuação do professor especializado em Educação Física pode ser notada, de forma significativa, nos espaços públicos, criados exclusivamente com vistas à prática de atividades físicas e desportivas da juventude sul-rio-grandense, a que se chamaram Praças de Desportos ou Praças de Educação Física ${ }^{8}$. Seguida por uma série de outras construções semelhantes, espalhadas pelas diversas regiões do Estado, a primeira destas praças criadas no Rio Grande do Sul, data do ano de 1926 e se localizava na capital, a saber, a Praça General Osorio, mais conhecida como "Alto da Bronze". Ao que consta, a municipalidade de Bagé também despontava, em cenário estadual, nesta nova empreitada da educação (UMA BRILHANTE DEMONSTRAÇÃO DE EDUCAÇÃ̂O PHYSICA, 1925).

Cabe destacar que, no interior destas praças, foram também construídos os chamados "Jardins de Recreio", que se destinavam, em especial, à atenção ao público dos menores, compreendido na faixa etária de três a seis anos. Por serem tais Jardins considerados um complemento à escola, estavam estrategicamente localizados junto aos colégios ou em suas imediações. Como exemplo, citamos

\footnotetext{
${ }^{8}$ Alguns documentos consultados ainda trazem a denominação "Praça de Sports". Sobre o tema, ler: CUNHA, M.L.O. As práticas corporais e esportivas nas praças e parques públicos da cidade de Porto Alegre (1920-1940). Dissertação de Mestrado defendida no ano de 2009, no Programa de Pós-Graduação em Ciências do Movimento Humano da UFRGS.
} 
o caso da construção do Jardim de Recreio n. 1 que, situado na Praça General Osorio, fazia frente ao Colegio Fernando Gomes, e distava apenas quatro quadras da antiga Escola Normal, do "Gymnasio Anchieta", do "Colegio do Rosario" e do "Collegio Elementar" (EDUCAÇÃO PHYSICA, 1929, n.).

Tais espaços eram dotados de brinquedos, campos e piscinas onde, ao exercitarem-se constantemente e de forma lúdica, os pequenos estariam robustecendo os músculos e preparando uma "juventude forte, hygida, apta a arrostar as vicissitudes da vida actual" (A EDUCAÇÃO PHYSICA NO RIO GRANDE DO SUL, 1937, p. 59). Importa destacarmos que ambas as iniciativas educacionais foram trazidas ao Rio Grande do Sul pelas mãos do Prof. Guilherme Gaelzer que, após visitas e estudos em países estrangeiros, da América e da Europa, irradiou ao Estado os modernos conhecimentos que lá adquiriu acerca dos rumos da nova, científica e eficiente Educação Física.

No rol dos espaços de atuação a que se destinou o professorado egresso do curso intensivo, sua presença se consagrou, também, nos eventos cívicos conhecidos por "Semana da Raça". Guiada pelos mesmos objetivos que motivaram à criação das praças e jardins de recreio, a Semana da Raça constituiu-se numa festividade cívica, também criada pelo governo do Estado, no ano de 1933, na qual a grandeza e a força da "raça brasileira" vinham à tona por meio de demonstrações e evoluções físicas realizadas por escolares, e pela prática concentrada de exercícios físicos ao longo dos dias que compunham o período estipulado. O "aprimoramento racial, a formação de um typo ethnico perfeito, bem compleicionado, desenvolto" (A EDUCAÇÃO PHYSICA NO RIO GRANDE DO SUL, 1937, p. 59), encerravam os objetivos principais do evento9.

Ao que se mostra, o governo do estado do Rio Grande do Sul adiantava-se, em cenário nacional, na incorporação dos ideais iluministas de livre movimentação corporal, tão defendidos pela Nova

\footnotetext{
${ }^{9}$ Não raras vezes foram encontradas nas páginas da Revista do Globo imagens do professor Gaelzer e suas alunas na semana da pátria, reforçando a idéia do citado movimento de aprimoramento racial.
}

Movimento, Porto Alegre, v. 16, n. esp., p. 37-60, 2010. 
Pedagogia que se instalava no país. Assim, é possível afirmarmos que a década de 1930 foi significativa para a Educação Física brasileira. Com o incontestável valor de sua participação na formação de uma nação forte, os gôvernos, indiferentemente de suas formas, foram obrigados a olhar com carinho e a legislar cuidadosamente para êste setor da educação brasileira.

Deste modo, o chefe do governo rio-grandense não poderia ficar indiferente ao movimento nacional que se delineava em prol do desenvolvimento da Educação Física. Neste caminho, constrói-se a argumentação justificando a criação do Departamento Estadual de Educação Física (DEEF):

Considerando físico da mocidade que a constituição federal, no seu art. 131, estabelece que a educação física será obrigatória em todas as escolas primárias, normais e secundárias do país e, no art. 132 determina que o estado auxilie e proteja as associações destinadas ao adestramento e a sua projeção no futuro do indivíduo e da nação, por isso; Considerando que se impõem a creação de um órgão técnico com o fim de dirigir, orientar e fiscalizar a prática da educação fisica não só nos institutos de ginástica e nas agremiações desportivas do estado; por outro lado; Considerando ser de imperiosa necessidade formar pessoal técncico em educação física e desportes, de forma a poder ministrar a indispensável instrução sem os graves inconvenientes oriundos da falta de conhecimentos especializados (FRANCO; SILVA; SCHIDROWITZ, 1940, p. 637).

$\mathrm{Na}$ agitação dos ares de transformação que atravessavam o momento, foi assim criado, então, o DEEF, subordinado à Secretaria de Estado da Educação com a atribuição de dirigir, orientar e fiscalizar a prática da educação física nos estabelecimentos de ensino, oficiais e particulares, nos institutos de ginástica e nas agremiações desportivas do Estado. Era o último ano da década de 1930, e as ondas que precederam a este período agitaram-se anunciando novos tempos para a Educação Física no Rio Grande do Sul. 
Deste modo, podemos afirmar que as estratégias alçadas pelo governo do Estado para amenizar o quadro de defasagens inicialmente descrito, iniciaram ainda em 1929, quando, sob o governo do então Presidente ${ }^{10}$ do Rio Grande do Sul, Getúlio Vargas (19281930), foi criado o "Curso de Educação Physica", na capital. Não podemos, no entanto, assegurar com precisão o número concreto de reedições do referido Curso, nem mesmo o ano exato da formação de sua última turma. O que nos remete as fontes consultadas é que, até o ano de 1937, o referido curso havia formado 288 professores que propagavam "ensinamentos através de todo o Estado, contribuindo para a melhoria das condições de saude (sic) do povo" (A EDUCAÇÃO PHYSICA NO RIO GRANDE DO SUL, 1937, p. 59).

\section{Considerações FinaIs}

Os elementos que aqui apresentamos, acerca da constituição inicial do campo de formação de professores de Educação Física, no estado do Rio Grande do Sul, no período da Primeira República, são parte de uma caracterização mais ampla e detalhada que ainda incluiria outros aspectos que não pudemos aqui abordar, por conta da organização formal deste artigo. No entanto, a partir do exposto, acreditamos que já se possa construir uma noção sobre a trajetória de formação profissional em terras sul-rio-grandense e, no mesmo movimento, esperamos que tais noções, para muitos ainda desconhecidas, alimentem novas pesquisas e questionamentos acadêmicos.

Desta forma, o estudo destes cursos iniciais de formação, aqui exposto de uma forma muito breve, está sendo realizado com maior demora e cuidado nas pesquisas realizadas pelo Núcleo de Estudos em História e Memória do Esporte e da Educação Física (NEHME), núcleo este vinculado à Escola de Educação Física desta universidade. Trazer ao conhecimento do público acadêmico o nosso passado

\footnotetext{
${ }^{10}$ Denominação corresponde aos governadores dos estados brasileiros, no período da República Velha.
}

Movimento, Porto Alegre, v. 16, n. esp., p. 37-60, 2010. 
profissional é reconhecer a circularidade do processo que nos forma a cada dia, e que muito determina, seja pela posição ou pela oposição, o futuro que nos convida constantemente a contemplar e a transformar aquilo que poderemos ser. 
The School of Physical Education and the field of teacher training in the state of Rio Grande do Sul: the origins of specialized training (18691929)

Abstract: ESEF's foundation is inset in a social process, in which Rio Grande do Sul's society was mobilized to reach the purposes that, even before correspond to its social particularities, remitted to the consolidation of a new Brazil, country that was emerging as a republican political organization. Thus, in our thinking, any attempt to distinguish ESEF as the first teaching institution to graduate teachers in higher education in the state, passes through, necessarily, by the knowledge of the efforts for the systematization of this formative practice, which anteceded its arrival to the field. Therefore, the central aim of the study was to comprehend how occurred Physical Education teachers' formation in the previous period of ESEF institutionalization. Intending to do so, the recognition and the validity of new versions about our study object, and also the utilization of sources that announce provenances and diverse natures are elements that compose a particular form of history appropriation, of which we search to approximate here: Cultural History. In this spectrum, our investigations about this theme leaded us to punctuate two significative moments which have crossed the field in these initial moments: the absence of specialty formation and, from the year of 1929, the organization of the so-called "Physical Education Intensive Courses".

Keywords: History. Physical Education. Teachers' formation. 
La Escuela Superior de Educación Física y el campo de la formación de profesores del estado de Rio Grande do Sul: los orígenes de la formación especializada (1869-1929)

Resumen: La fundación de la ESEF está insertada en un proceso social, en lo cual la sociedad de Rio Grande do Sul fue movilizada para el alcance de finalidades que, antes mismo de corresponder a sus particularidades sociales, eran remitidas a la consolidación de un nuevo Brasil, país que, entonces, emergía como una organización política republicana. Así, en nuestro entendimiento, cualquier tentativa de distinguir la ESEF como primera institución de enseñanza a formar profesores en nivel superior en el estado, pasa, necesariamente, por el conocimiento de los esfuerzos de sistematización de esta práctica formativa, que precedieron a su llegada al campo. De tal modo, el objetivo central del estudio fue comprender como ocurrió la formación de profesores de Educación Física en el periodo anterior a la institucionalización de la ESEF. Para tanto, el reconocimiento y la validad de nuevas versiones acerca de nuestro objeto de estudio, bien como la utilización de fuentes que anuncien procedencias y naturalezas diversas son elementos que componen una forma particular de apropiación de la historia, de la cual procuramos aquí nos acercar: la Historia Cultural. En este espectro, nuestras investigaciones acerca del tema nos llevaron a puntuar dos momentos significativos que atravesaron el campo en estos momentos iniciales: la ausencia de formación especializada y, a partir del año 1929, la organización de los Ilamados "Cursos Intensivos de Educación Física".

Palabras-clave: Historia. Educación física. Formación de profesores. 


\section{REFERÊNCIAS}

ARANHA, O. Relatório apresentado ao Presidente do Estado do Rio Grande do Sul Getulio Vargas. Porto Alegre: A Federação, 28 ago 1929.

BOMBASSARO, T.; VAZ, A. F. Educação do corpo e formação de professores para a Educação Física em Santa Catarina (1937-1945). In: COLÓQUIO LUSOBRASILEIRO DE QUESTÕES CURRICULARES, 4., Florianópolis, 2008. Anais...

BOURDIEU, P. Os ritos de instituição. In: BOURDIEU, P. A economia das trocas lingüísticas: o que falar quer dizer. 2 ed. São Paulo: EDUSP, 1998. p. 97-106.

BOURDIEU, P.; PASSERON, J. C. A reprodução: elementos para uma teoria do sistema de ensino. 3. ed. Rio de Janeiro: Francisco Alves, 1992.

BRASIL. Constituição Federal de 1937.

Decreto n. 14.784 de 1921. Dispõe sobre a substituição do Método Alemão pelo Método Francês e, concomitantemente, a adoção, deste último, como o "método oficial" a ser incorporado no país, enquanto não fosse criado o próprio "Método Nacional".

CALVINO, I. Palomar. 2. ed. São Paulo: Cia das Letras, 2004.

CASTELLANI FILHO, L. Educação Física no Brasil: a história que não se conta. Campinas: Papirus, 1994.

CASTILHOS, J. P. Mensagem enviada à Assembléia dos representantes do estado do Rio Grande do Sul, Porto Alegre. Typographia de Cesar Reinhardt, 20 set 1895.

Mensagem enviada à Assembléia dos representantes do estado do Rio Grande do Sul, Porto Alegre: Typographia de Cesar Reinhardt, 20 set 1897.

Mensagem enviada à Assembléia dos representantes do estado do Rio Grande do Sul, Porto Alegre: Typographia de Cesar Reinhardt, 20 set 1896.

CUNHA, M. L. As práticas corporais e esportivas nas praças e parques públicos da cidade de Porto Alegre (1920-1940). Dissertação (Mestrado em Ciências do Movimento Humano) - Escola de Educação Física, Universidade Federal do Rio Grande do Sul. Porto Alegre, 2009.

DURKHEIM, E. Educação e sociologia. 11. ed. São Paulo: Melhoramentos, 1978.

A EDUCAÇÃO physica: a creação de um curso intensivo. Correio do Povo, 1929. 
FRANCO, A.; SILVA, M.; SCHIDROWITZ, J. (Org.). Porto Alegre: biografia duma cidade. Porto Alegre: Tipografia do Centro, 1940.( Livro Comemorativo do Bicentenário da Fundação da Cidade)

LYRA, V. B. Escola Superior de Educação Física de Florianópolis e o campo da formação de professores no estado catarinense: uma história, um olhar, uma identidade. 2009. Dissertação (Mestrado em Educação) - Centro de Ciências da Educação, Universidade Federal de Santa Catarina. Florianópolis, 2009.

MAZO, J. Z. Memórias da Escola Superior de Educação Física da Universidade Federal do Rio Grande do Sul (ESEF/UFRGS): um estudo do período de sua fundação até a federalização (1940-1969). Movimento, Porto Alegre, v. 11, n. 1, p. 143167, jan./abr. 2005.

MAZO, J. Z.; LYRA, V. B. Nos rastros da memória de um "mestre de ginástica". Motriz, Rio Claro, v. 16, n. 4, p. 967-976, out./dez. 2010.

MELO, V. A. de. Escola Nacional de Educação Física e Desportos: uma possível história. 1996. 220f. Dissertação de (Mestrado) - Faculdade de Educação Física, Universidade Estadual de Campinas. Campinas, 1996.

EDUCAÇÃO PHYSICA. O Estado de São Paulo, 1929.

OS MODERNOS Methodos de ensino. O Esporte, 1929.

PICCOLI, J. C. J. Educação Física Escolar: marcos internacionais e nacionais de memória. In: DACOSTA, L. P. da. (Org.). Atlas do Esporte no Brasil. Rio de Janeiro: Shape, 2005. p. 503-510.

Educação Física na escola pública do Rio Grande do Sul: antecedentes históricos (1857-1984). Pelotas: Editora da UFPEL, 1994.

A EDUCAÇÃO PHYSICA NO RIO GRANDE DO SUL. Revista de Educação Physica, n. 11, 1937, p. 59.

GINÁSIO CRUZEIRO do Sul. Revista do Ensino. V. 2, n. 7, mar 1939.

RIO GRANDE DO SUL. Constituições do Estado do Rio Grande do Sul. Porto Alegre: Instituto de Informática Jurídica da Procuradoria Geral do Estado, 1990. v. 1.

Decreto n. 89, de 02 de fevereiro de 1897. Dispõe sobre a reformulação do ensino público primário e secundário no estado do Rio Grande do Sul.

UMA BRILHANTE demonstração de Educação Physica. Correio do Povo, Porto Alegre, 1925.

VIEIRA, C. E. O discurso da modernidade: I Conferência Nacional de Educação (Curitiba - 1927). In: CONGRESSO BRASILEIRO DE HISTÓRIA DA EDUCAÇÃO, 3., Curitiba, 2004. Anais... 1 CD-ROM. 
